\title{
IDENTIDADE CULTURAL E GESTÃO PARTICIPATIVA NA ÓTICA DO TURISMO
}

\author{
Autores: \\ Camila de Brito Antonucci Benatti Braga. \\ Instituto de Geografia e Ordenamento do Território \\ Universidade de Lisboa. \\ Portugal \\ camilabenatti@hotmail.com \\ Mirella Caetano de Souza \\ Instituto Federal de Educação, Ciência e Tecnologia do Amazonas - IFAM \\ mi_souza@hotmail.com \\ Leandro Benedini Brusadin \\ Universidade Federal de Ouro Preto \\ leandro@turismo.ufop.br
}

\section{RESUMO}

A cultura é uma forma de percepção de uma realidade representada por determinados símbolos. O turismo pode reutilizar uma dada cultura por meio do patrimônio cultural. Todavia, a atividade turística pode degradar os bens patrimoniais de um local e afetar sua identidade cultural. Pretende-se então, mostrar neste trabalho, como estes danos podem ser minimizados se os "proprietários" de tal legado se inserirem no processo de gestão do turismo, pois, como autóctones, podem cuidar do que é característico de sua cultura e proteger sua herança. Por meio de pesquisas bibliográficas e análise de dois estudos de caso, concluiu-se que as ações conjuntas entre a indústria turística e a população local são imprescindíveis para a manutenção das premissas defendidas no presente artigo. Deste modo, essas comunidades podem proteger e preservar os seus bens, criando também um relacionamento harmonioso entre visitantes e anfitriões por meio de um planejamento integrado e a execução conjunta da atividade turística.

Palavras-chave: turismo; cultura; gestão participativa; processo identitário. 


\title{
CULTURAL IDENTITY AND SHARED MANAGEMENT FROM THE TOURISM PERSPECTIVE
}

\author{
Autores: \\ Camila de Brito Antonucci Benatti Braga. \\ Instituto de Geografia e Ordenamento do Território \\ Universidade de Lisboa. \\ Portugal \\ camilabenatti@hotmail.com \\ Mirella Caetano de Souza \\ Instituto Federal de Educação, Ciência e Tecnologia do Amazonas - IFAM \\ mi_souza@hotmail.com \\ Leandro Benedini Brusadin \\ Universidade Federal de Ouro Preto \\ leandro@turismo.ufop.br
}

\begin{abstract}
Culture is a form of perception of reality represented by certain symbols. Tourism can reuse a given culture through the cultural heritage. However, tourism can degrade local heritage and affect its cultural identity. The purpose of this study is then to show how the damage motivated by the tourism can be minimized if the "owners" of such a legacy fit within the process of tourism management, because as natives they must take care of what is characteristic of their culture and protect their heritage. Through literature research and analysis of two case studies, it's possible to achieve the conclusion that joint efforts between the tourism industry and local people are essential to the maintenance of the premises defended in this article, so that these communities can protect and preserve their assets, also creating a harmonious relationship between visitors and hosts through an integrated planning and joint implementation of tourism.
\end{abstract}

Key words: tourism; culture; participatory management; identity process. 


\title{
IDENTIDAD CULTURAL Y GESTIÓN PARTICIPATIVA EN LA ÓPTICA DEL TURISMO
}

\author{
Autores: \\ Camila de Brito Antonucci Benatti Braga. \\ Instituto de Geografia e Ordenamento do Território \\ Universidade de Lisboa. \\ Portugal \\ camilabenatti@hotmail.com \\ Mirella Caetano de Souza \\ Instituto Federal de Educação, Ciência e Tecnologia do Amazonas - IFAM \\ mi_souza@hotmail.com \\ Leandro Benedini Brusadin \\ Universidade Federal de Ouro Preto \\ leandro@turismo.ufop.br
}

\section{RESUMEN}

La cultura es una forma de percepción de una realidad representada por determinados símbolos. El turismo puede reutilizar una determinada cultura a través del patrimonio cultural. Sin embargo, la actividad turística puede degradar los bienes patrimoniales de un local y afectar su identidad cultural. Se pretende entonces, mostrar en este trabajo, cómo estes daños pueden ser minimizados si los "dueños" de tal legado si insertan en el proceso de gestión del turismo, pues, cómo autóctonos, pueden cuidar del que es característico de su cultura y proteger su herencia, creando al mismo tiempo, el sentido de pertenencia y valorización de sus bienes. A través de búsquedas bibliográficas y análisis de dos estudios de caso, llegó a la conclusión de que acciones conjuntas entre la industria del turismo y la población local son esenciales para el mantenimiento de las premisas defendidas en el presente artículo, para que así, esas comunidades puedan proteger y preservar sus bienes, creando también una relación armoniosa entre visitantes y anfitriones a través de una planificación integrada y la ejecución conjunta de la actividad turística.

Palabras claves: turismo; cultura; gestión participativa; proceso de identidad. 


\section{INTRODUÇÃO}

Este artigo é dedicado ao estudo da relação entre identidade, gestão participativa e turismo, para isso será dividido em três seções que abordarão os seguintes temas: a primeira aborda a temática acerca da Identidade Cultural na Pós-modernidade relacionando-a com cultura e turismo, e por conseguinte, nesta mesma seção, se discorre sobre o patrimônio como instrumento da memória e processo identitário; posteriormente, na segunda parte, se desencadeia um debate acerca da ação da comunidade local no desenvolvimento e no processo turístico; Ao fim, é feita a análise de dois estudos de caso tratando sobre o tema em questão, na qual são feitas algumas recomendações e reflexões acerca da investigação realizada, seguida das considerações finais.

A investigação foi realizada por meio de pesquisas em fontes teóricas bibliográficas, e dois estudos de casos foram analisados através destas bibliografias e de documentos impressos e online. No caso 1, o primeiro autor teve contato in locus durante o estágio obrigatório exigido em sua graduação, na cidade de Boa Esperança, onde pôde ter um breve contato com o local investigado. Assim, foi estudado a Casa da Cultura e Biblioteca Municipal de Boa Esperança, Minas Gerais, e sobre o Conselho de Patrimônio Histórico e Cultural do município, cujos passam por dificuldades em conseguir novos associados que tenham interesse em dirigir e manter a gestão e a proteção de seus bens.

O segundo caso foi um estudo baseado em fontes bibliográficas e websites sobre a Fundação Casa Grande - Memorial Homem Kariri, localizados na região do Cariri na cidade de Nova Olinda, localizada no Estado do Ceará. Esta Fundação reúne crianças, jovens e pais da região com intuito educacional e de gestão social. A FCG tem como meta levar a educação ao "mundo do sertão", onde trabalham com programas de Memória, Artes, Comunicação e Turismo. Ao contrário do primeiro estudo, este é um caso de sucesso, onde a população local atua no desenvolvimento das atividades juntamente com outros atores.

Espera-se com este trabalho, auxiliar os profissionais de turismo e a população residente de locais turísticos a instituírem ações conjuntas com o objetivo de proteger e preservar os seus bens, além de criar um bom relacionamento entre visitantes e anfitriões, 
através de um bom planejamento e da execução conjunta entre os agentes e atores que envolvem esta atividade.

\section{Identidade, Cultura e Turismo}

Apreendem-se por identidade comum de um povo as suas características específicas que são compartilhadas em uma nação ou localidade, aspectos estes que, segundo Cláudio Batista (2005), formam uma identidade particular. A identidade pode estar ligada à religião, costumes, etnias, crenças, gênero, idade e classe social. Para determinar a identidade cultural de uma sociedade, segundo Santos (2004), é preciso diferenciar as suas características em relação a outras identidades e culturas diversas.

No final do século $\mathrm{XX}$ as sociedades passaram por uma transformação estrutural que ocasionou mudanças e fragmentações sócio-culturais. Segundo Stuart Hall (2006), estas transformações mudaram nossas identidades pessoais, perdendo a idéia de sujeito integrado, do que era sólido, ocasionando o que é chamado de deslocamento ou descentração do sujeito. "Esse duplo deslocamento - descentração dos indivíduos tanto de seu lugar no mundo social e cultural quanto de si mesmos - constitui uma 'crise de identidade' para o indivíduo" (Hall, 2006, p. 9).

O que está em evidência é que o sujeito está composto de várias identidades, que vai adquirindo através de interconexões com outras culturas e costumes, podendo obter como consequência crises de identidades e contradições do seu eu. Na modernidade, as identidades nacionais subordinam as identidades individuais, todavia, essas estão se deslocando e comprimindo distâncias e tempo. Esse colapso cultural e identitário estão diretamente vinculados ao processo de globalização (Hall, 2006).

Como consequência dessa reestruturação nas sociedades e de influências externas, as identidades locais têm adquirido grande relevância, e novas identidades hibridizadas têm surgido. Dessa forma, a cultura nacional antes tão centrada, tem se fragmentado. Isto é, através do intercambio cultural as identidades hibridizadas têm produzido culturas novas e complexas. Assim, no item que se segue, apresentar-se-á uma discussão sobre o papel da comunidade na conservação do patrimônio cultural para a manutenção da 
memória social, e para reforçar a identidade cultural dessa mesma comunidade.

A fim de contribuir para a discussão das ideias, torna-se relevante expor os principais debates que giram em torno da cultura. Portanto, para Peter Burns (2002, p. 73), a cultura abrange "tudo o que constitui a sociedade humana", como identidades étnicas, modo de vida, gêneros, relações entre homens e familiares. Para a Antropologia Social, cultura é como um código específico de um grupo de pessoas, do qual exprime suas tradições, os modos de vida, de pensar e agir. Permite traduzir as diferenças entre povos e pessoas, possibilitando resgatar a nossa humanidade, no outro, de forma recíproca. (Da Matta, 1981).

De certo modo, poderíamos dizer que 'cultura é tudo', incluindo a experiência socialmente aprendida, instituições sociais, ciência, arte etc. A lista prossegue e inclui, é claro, aspectos ligados tanto com a recepção de turistas quanto com a condição de ser um turista (Burns, 2002, p.74).

O trabalho de Ulpiano T. B. de Meneses (1996) destaca quatro proposições sobre o conceito de cultura. A primeira delas refere-se à cultura como o universo da escolha, da seleção e da opção. A segunda destaca que o universo da cultura é historicamente criado, por isso os sentidos e valores que o sustentam precisam ser explicados, declarados e propostos. A terceira reforça a ideia de que o valor cultural não está nas coisas, mas é produzido pelo jogo concreto das relações sociais. A quarta proposição afirma que as políticas culturais devem dizer respeito à totalidade da experiência social e não apenas a segmentos seus privilegiados.

O termo cultura é um termo muito utilizado nas abordagens antropológicas e foi apropriado pela Nova História Cultural (NHC). O antropólogo Bronislow Malinowski (1975, p. 43) já havia definido cultura de maneira ampla, "abrangendo as heranças de artefatos, bens, processos técnicos, ideias, hábitos e valores”. Outro antropólogo que teve grande influência nessa concepção foi Clifford Geertz (1989, p. 52), que em sua "teoria interpretativa da cultura", define o termo como "o padrão, historicamente transmitido, de significados incorporados em símbolos, um sistema de concepções herdadas, expressas em formas simbólicas, por meio das quais os homens se comunicam, perpetuam e desenvolvem seu conhecimento e suas atitudes acerca da vida". Esse também 
é o conceito de cultura ao qual adere Roger Chartier (1990), e que se distancia da proposta hermenêutica, incorporando o conceito de representações da realidade.

A cultura seria o referencial básico para o estudo do comportamento do homem dentro de um grupo. Os simbolismos desse grupo, como a arte, a linguagem e os gestos, são uma dinâmica de construção, de transmissão e de renovação da cultura. Assim, a cultura constitui uma forma de explicação dos fenômenos contextuais. É resultado da invenção social e é transmitida e apreendida somente por meio da comunicação e da aprendizagem (Martins e Leite, 2002).

Na Idade Média, intelectuais e estudiosos aristocratas, viajavam pela Europa com o intuito de pesquisas, aprendizado e contemplação de obras de artes e monumentos, essas viagens receberam o nome de Grand Tour. Nota-se desde aquela época a relação entre turismo e cultura, quando estes estudiosos que liam sobre a existência de sítios e artes, sentiam o desejo de identificar no local aquilo do que tinham conhecimento, desfrutando o anseio de visualizar o seu imaginário. Mais tarde, entre os anos de 1765 e 1820, o Grand Tour deixa de lado o caráter de conhecimento educacional e atinge uma característica mais mundana, prazerosa, havendo um aumento nas diversidades dos atrativos culturais e se aproximando dos fundamentos do turismo atual (Vasconcelos, 2006).

Pode-se situar a origem da relação entre turismo e cultura no grand tour europeu, quando os aristocratas e mais tarde a burguesia viajavam principalmente para contemplar monumentos, ruínas e obras de arte dos antigos gregos e romanos (MTur, 2006, p.9).

De acordo com Camilo Vasconcelos (2006), no século XIX o turismo já era considerado um fenômeno, uma atividade em expansão. Nessa época, na Europa, o patrimônio cultural se consolidou, atraindo turistas de vários lugares do mundo. Através das literaturas de viagens e românticas, houve a propagação do conhecimento do patrimônio e de sua preservação como identidade de um povo ou de uma nação. No final deste mesmo século, notaram que a junção entre turismo e legado cultural era positiva, sendo esta consolidação chamada pelo turismo cultural de circuito clássico. 
Em 1998, a UNESCO realizou em Paris uma reunião denominada 'Cultura, Turismo e Desenvolvimento - Desafios para o Século XXI'e nela foi declarada que 'qualquer forma de turismo produz um efeito cultural tanto no turista como no anfitrião'. Assim é natural que os turistas passem a buscar a prática do chamado turismo cultural. (Vasconcelos, 2006)

O setor turístico tem se diversificado em segmentos, no qual o termo Turismo Cultural tem tomado lugar significativo. Este proporciona ao indivíduo um intercâmbio cultural, rico em conhecimentos e experiências. Os turistas que procuram por este tipo de turismo têm como principal objetivo conhecer obras artísticas, tradições étnicas e os bens materiais e imateriais de uma localidade, região ou país, ou de um determinado grupo, proporcionando vivências de situações e aspectos da identidade cultural de uma população.

Ao tentar aproximar o conceito antropológico de cultura ao turismo, podemos afirmar que a atividade turística promove relações sociais das quais geram interações e transmissão de tradições culturais, possibilitando a globalização da cultura. $\mathrm{O}$ fenômeno passou a servir como ferramenta de desenvolvimento econômico e preservação do legado cultural de muitos países e localidades, pois ao mesmo tempo em que oferece empregos e gera renda para a comunidade receptora, ele também possibilita a conservação do seu patrimônio e a valorização da identidade local. Assim, o turismo utiliza a cultura como um meio de atração e renda, e a cultura por sua vez utiliza o turismo como forma de valorização e conhecimento de sua herança e identidade. Deste modo, se insere o conceito de representações de Chartier (1990), na qual a realidade é representada, sendo a própria cultura e o turismo frutos de invenções ou imaginações.

Alguns autores afirmam que, ao atrair a atenção para o patrimônio natural ou cultural, o turismo promove sua conservação e valorização. Há também uma idéia romântica que está muito em voga na atualidade, proveniente dos séculos XVIII e XIX: de que o turismo gera e promove a harmonia entre os povos, sendo inclusive assumida pela UNESCO, quando afirma que o turismo promove um diálogo mais rico entre as culturas (Vasconcelos, 2006, p.33 e 34). 
A tradição construída na idade moderna e que se torna hegemônica até meados do século passado (o século XX) é a de tomar como patrimônio cultural as grandes construções culturais e identitárias, comumente associadas às obras monumentais de uma arte ligada às classes dominantes. Principalmente com elo à arquitetura, escultura, pintura, literatura (incluído o teatro) e a música. Além disso, os grandes fatos da história nacional (ou regional), especialmente aqueles ligados aos grandes feitos políticos, eram tomados como os verdadeiros fatos históricos de herança. Dessa tradição, inclusive, vem o uso da palavra patrimônio no lugar de outras de significado mais ampliado, como herança e legado (Menezes, 2004).

Os elementos culturais podem servir como meios de atrair visitantes e recursos para o desenvolvimento econômico de uma localidade. No entanto, a atividade turística deve ser realizada de modo sustentável, para que o legado cultural e seus atrativos não sejam descaracterizados ou sofram alterações, simplesmente para atender a demanda turística, tornando-se, prioritariamente, um produto para comercialização em vez de um meio de valorização cultural. Portanto, a preocupação é que a atividade turística possa se massificar e com isso degradar tanto o legado cultural material, quanto influenciar na cultura imaterial manifestada pela população receptora.

O turismo pode servir assim, como ferramenta de revalorização da identidade local, sendo uma oportunidade de fortalecimento da cultura e tradição de um povo, com o intuito de preservar suas origens e sua história, de modo a resguardar e revitalizar o seu patrimônio. Para tanto, também é necessário afirmar que as sociedades pós-modernas se caracterizam pelo seu hibridismo cultural, sendo o turismo uma das forças que direcionam esta concepção. Deste modo, este patrimônio é invenção desta sociedade, assim como, a atividade turística.

No turismo cultural a memória e a identidade são essenciais para o desenvolvimento deste segmento turístico, que vem crescendo a cada década devido às exigências dos padrões do turismo, no caso cultural, pois um dos fatores que faz crescer esse tipo de turismo é a elevação da escolaridade da população que de uma forma ou de outra vem aumentando graças a esse mundo globalizado (Batista, 2005, p.33). 
Pierre Nora (1993) utiliza o conceito de "lugares de memória", partindo do pressuposto de que não há memória espontânea, de que é necessário criar arquivos, que é preciso manter aniversários, organizar celebrações, pronunciar elogios fúnebres, notariar atas, porque essas operações não são naturais. Desta forma, o turismo é um modo de representação dos lugares de memória, no qual os visitantes o entendem como conhecimento de uma dada realidade social e histórica. A cultura utiliza a memória e a identidade para preservá-la e motivar o turismo, ressalta-se então que este tipo de atividade atinge um público com um nível de instrução educacional alto, que quer conhecer, experimentar e vivenciar a história de um local ou de um grupo social.

\section{Comunidade e os Turistas: atores sociais do desenvolvimento}

A partir da década de 1960, o turismo começa a ser considerado como alternativa de desenvolvimento mundial. No entanto, a atividade foi mal elaborada em vários lugares, acontecendo de forma desordenada, ocasionada pela visitação descontrolada, pela falta de respeito por parte desses visitantes e, principalmente, pela escassez de recursos humanos especializados (MTur, 2006).

Realizada dessa forma, o desenvolvimento da atividade turística com um foco cultural, pode gerar um processo de mercantilização da cultura e de seu legado na comunidade receptora. Para Margarita Barretto (2001), dentro do fenômeno turístico, o fator que merece mais atenção é o receptivo local, como a prestação de serviços ao turista e todas as relações que ocorrem entre visitantes e residentes.

O cotidiano local, mais que estimulador de curiosidade, é elemento problematizador do objeto que se brusca fruir, e as intermediações que se fazem entre a cultura passada e o cotidiano é o que possibilita o entendimento, a contextualização instigante e a memorização prazerosa, que permanece na mente, revive o momento da compreensão e estimula a busca de novos entendimentos e de novos prazeres (Menezes, 2004).

Os turistas ao chegarem a uma localidade, tendem a impor-se sobre os residentes, como se fossem "donos" do local, desrespeitando os seus respectivos habitantes (Castro, 
2002). Geralmente, os turistas não estão preocupados em estabelecer relações com os indivíduos locais. No entanto, ao agirem desse modo, produzem um sentimento de inferioridade e hostilidade nos autóctones. Esse modo de ação deve ser mudado, para que a atividade turística se desenvolva de forma harmoniosa entre visitantes e residentes. De acordo com muitos pesquisadores o turismo trabalha na manutenção de relações pacíficas, para a interação com a cultura e a vida do outro. Para Krippendorf (2003), o turismo permite o encontro entre seres humanos pertencentes a culturas e criações distintas, operando em prol da aproximação e compreensão entre os povos.

Porém, uma situação negativa que o turismo pode despertar é o sentimento de inferioridade por parte do residente, de preconceito por parte do visitante e de desconfiguração do modo de vida da comunidade local. Se por um lado o turista está em férias e disposto a gastar, por outro lado, o residente está em dia comum de trabalho e esforço diário. Ou seja, não está desfrutando do mesmo conforto e lazer, e muitas vezes não tem o recurso financeiro semelhante ao do turista. Ademais, se a comunidade for mais humilde, o turista pode se mostrar preconceituoso evitando o contato com os residentes. Outro fator é que em muitos locais turísticos a população incorpora novos estilos de vida, se reestruturando e desconfigurando o seu modo tradicional de vida para atender aos visitantes e se adaptarem à atividade turística. Isso é considerado como um aspecto negativo, pois causa perda da identidade cultural e descaracterização das tradições e dos modos de vida, desdenhando e entrando num processo de esquecimento de seus valores e história.

Sob este aspecto crítico do turismo, recorremos a Luzia Neide Coriolano en Martins et al. (2006), a qual situa o turismo como uma das mais novas modalidades do processo de acumulação, que vem produzindo novas configurações geográficas e materializando o espaço de forma contraditória pela ação do Estado, das empresas, dos residentes e dos turistas. O turismo para se reproduzir, segue a lógica do capital, quando poucos se apropriam dos espaços e dos recursos neles contidos, apresentando-os como atrativos transformados em mercadorias.

Por outro lado, um aspecto positivo é a troca de conhecimentos e o intercâmbio cultural, que proporcionam evolução psicológica, intelectual e pessoal, pois o diálogo 
entre turistas e população local pode trazer inúmeros benefícios para ambos, desde que haja respeito, educação e boa vontade. As trocas culturais proporcionadas pela atividade turística podem ser catalisadoras do processo de auto-estima e valorização. Como? A partir do momento em que o turista dialogar com o autóctone, desejar conhecer as tradições locais e o seu modo de vida, e este, por sua vez, mostrar-se afetuoso e receptível, ambos vão entrar em sincronia mantendo uma relação harmoniosa. Assim, os anfitriões vão perceber, através do interesse e curiosidade do turista sobre sua cultura, o valor que possuem e, assim, despertar-se-á sentimento de pertença e auto-estima, o prazer em contar suas histórias, tradições e herança cultural.

Considerando, então, o patrimônio como a síntese simbólica dos valores identitários de uma sociedade que ela própria reconhece como próprios e sabe interpretar e preservar. Sob outro ângulo, ao tomar o patrimônio reconhecido como um documento histórico da memória que construímos e que reflete nossa capacidade de edificar uma cultura através do tempo, seria possível criar parâmetros de interpretação. Esses parâmetro deverão assumir formas que tenham como substrato a busca sensível de auscultar e ouvir a realidade e as vivências históricas dos habitantes dos locais onde, historiadores e turismólogos, atuam na construção de espaços de memória e de atrativos turísticos (MENEZES, 2004).

Para que isso aconteça, o turista deve agir de forma ética, ter respeito pela população residente e seus bens, sem degradar o meio ambiente e o seu legado cultural, levando do lugar novas experiências, aprendizado e conhecimentos. Assim que o turista deve agir na sociedade, com bom senso e educação, beneficamente. É preciso que haja o cuidado para que todos sejam favorecidos. "Quase ninguém tem a preocupação com as condições de vida dos autóctones, ou com a manutenção com o equilíbrio ecológico e os recursos naturais" (Krippendorf, 2003, 81).

Contudo, é essencial compreender que a integração, amiga e respeitável, entre visitantes e residentes, precisa ser elevada, proporcionando novos conhecimentos, apreensão de novas culturas e paz de diferentes povos, bem como a valorização do artesanato local e a geração de empregos. A aceitação da atividade em sua localidade pode trazer benefícios, seguida da vontade de participar e planejamento adequado, 
com o autóctone interagindo com o turista e vice-versa, de forma harmoniosa, paciente e respeitável à sua criação, costumes e modos de vida. Havendo esta compreensão, a atividade turística pode prosseguir de forma menos impactante, favorecendo a todos. Sendo assim, torna-se crucial verificar o papel da comunidade local no processo de desenvolvimento da atividade turística, visando a minimização de impactos da sua identidade cultural e de seus bens patrimoniais.

\section{A Ação Social da Comunidade no Processo Turístico}

Quando a cultura passa a ser um produto, é inevitável que seus "atrativos" (tangíveis ou intangíveis) sofram danos. Nesse sentido, é de tamanha importância que a população local se insira na gestão turística, de modo a trazer proteção da sua herança cultural, além da geração de renda e empregos.

O envolvimento dos indivíduos locais e o sentimento de pertença levam a comunidade a defender seus bens, de forma que os turistas não o degradem e de maneira que tragam benefícios econômicos para si.

No turismo comunitário, o interesse volta-se para o trabalho dos adultos para melhorar a renda das famílias, e as crianças são preservadas da antecipação do trabalho. As atividades turísticas comunitárias são associadas às demais atividades econômicas, com iniciativas que fortalecem a agricultura, a pesca e o artesanato, tornando estas atividades preexistentes ao turismo mais sustentável. Prioriza a geração de trabalho para os residentes, os pequenos empreendimentos locais, a dinamização do capital local, a garantia da participação de todos, dando espaço também às mulheres e aos jovens. Assegura a participação de pessoas das comunidades com o planejamento descentralizado e associativo [...] (Coriolano, 2009, p. 284).

O turismo pode se constituir como ferramenta de interpretação do patrimônio cultural, procedendo revitalizações de bairros e centros, de conjuntos arquitetônicos e monumentos para atender aos visitantes e conservar os bens da localidade. A participação ativa da população no planejamento e gestão do turismo pode trazer vários benefícios como: a preservação e conservação de seu legado cultural e de sua identidade; a elevação 
do conhecimento; auto-estima; valorização de suas tradições e de seu patrimônio; empregos; e avanço econômico. Para que isto ocorra, os indivíduos devem estar dispostos a participar e a se inserirem de forma atuante e bem planejada na atividade."O turismo comunitário é um processo de descoberta, quando a comunidade discute o que quer e o que pode fazer para o desenvolvimento das pessoas e do lugar". (Coriolano, 2009, p. 285).

Nessa perspectiva, é essencial que haja ações conjuntas entre o setor público, privado, profissionais especializados e a população local. Esta última deve se envolver agilmente, participando de conselhos administrativos do setor turístico, trabalhando dentro do trade, ou até mesmo se especializando através de cursos profissionais da área, para com isso se incorporar no planejamento e execução do setor. Para melhor compreensão desta dinâmica, Barretto (2002, pp. 49-51), menciona um exemplo da cidade de Colonia del Sacramento, no Uruguai, onde um bairro chamado Sur (Sul) de relevância histórica, era usado como zona de prostituição. Em 1969, foi criada uma comissão honorária do patrimônio dirigida por um arquiteto da comunidade que já mostrava interesse por esse bairro em suas pesquisas na faculdade. Esta comissão, em ação conjunta com o Ministério de Educação e Cultura, iniciaram pesquisas e escavações que após vinte anos vem produzindo grandes feitos para a cidade como recuperação histórica e restauração do bairro, empregando à Colonia o título de Patrimônio da Humanidade conferido pela UNESCO em 1996. Este é um exemplo, de como é necessário e importante a participação comunitária no processo turístico. Além do povo redescobrir sua história e desabrochar um sentimento de pertencimento, a atividade turística proporciona a partilha de benefícios dentro da comunidade, o desenvolvimento da economia e a geração de empregos. Hoje, este bairro é o principal atrativo turístico da cidade.

Como proceder então para que os indivíduos se engajem no processo de planejamento e implantação do turismo? Há várias formas de incentivá-los à participação, primeiramente, conscientizando-os e sensibilizando-os sobre a importância e o valor de sua herança cultural. Esta conscientização deve ser feita através de palestras, esclarecimentos públicos, reuniões ou conselhos. Devem ser apresentados nestas reuniões os projetos turísticos, as leis e os direitos de preservação e conservação do patrimônio, como também serem solicitadas sugestões, estimular as discussões sobre cidadania e 
educação patrimonial. É necessário e importante solicitar o engajamento da população no desenvolvimento e elaboração dos projetos, para que assim todos desfrutem dos benefícios e trabalhem juntos para a progressão da localidade. Nestas reuniões devem ser convocadas as presenças da comunidade, de lideranças locais e de instituições de ensino.

Assim exposto, parece um processo simples, porém, a realidade é complexa. Em muitos lugares há a convocação dos membros locais, todavia, poucos aparecem nos conselhos e reuniões. Portanto, torna-se difícil reunir as pessoas para desenvolvimento do turismo comunitário. Se elas não estiverem dispostas a participarem no desempenho da atividade, é custoso conceber o turismo de base local.

Essa dificuldade parece inerente no cenário brasileiro, onde a baixa cidadania é nossa herança histórica. Sant'Anna, Oliveira e Berenstein (2001) ressaltam esta questão analisando que é o Estado e a iniciativa estatal - e não a sociedade - que chegam primeiro ao Brasil. Ou seja, quem atravessa o oceano, no século XVI, é o Estado português patrimonialista - uma ordem burocrática através da qual o soberano está superposto ao Cidadão onde o Estado determina tudo e conduz a economia como se fosse empresa sua. É a partir disso que é possível explicar as raízes da falta de cidadania brasileira, e a confusão no Brasil entre o que é público e o que é privado, confusão que permanece até hoje.

No livro "Educação Ambiental para o Turismo Sustentável: vivências integradas e outras estratégias metodológicas", os autores (Matheus, Moraes e Caffagni, 2005) citam como exemplo o caso do Balneário Santo Antônio, localizado no município de Itirapina, São Paulo, onde foi elaborado um projeto para conservação ambiental da represa LoboBroa. Este projeto foi apresentado para as lideranças locais, para a Associação de Proprietários de Imóveis do Broa (APIB) e para as instituições de ensino. Para convocar os moradores para essa apresentação foram distribuídos 150 panfletos na portaria do Balneário e nos ônibus escolares. Além disso, foram afixados cartazes em pontos estratégicos do balneário, constando a discussão do projeto, o local, a data e o horário. O local, data e horário, foram designados da melhor forma, estrategicamente, para que a maioria comparecesse. Estiveram presentes na reunião somente 15 moradores. 
Como se pôde observar, ainda há muita falta de cooperação dos moradores locais na atividade turística. É importante que haja sensibilização da comunidade local, pois somente com a participação de considerável número de residentes é possível desenvolver a atividade turística de modo que esta proporcione benefícios compartilhados, a preservação e proteção de seu legado. Para Pessoa \& Rabinovici (2010) a intervenção da população no turismo leva à busca dos seus interesses econômicos, políticos, culturais e sociais. Deste modo, a seção seguinte aborda o uso turístico das localidades enquanto processo identitário e social, por meio da análise de dois estudos de caso.

\section{O Uso Cultural e Turístico das Localidades Enquanto Processo Identitário e Social: Casa da Cultura e Biblioteca Pública de Boa Esperança (MG) e Fundação Casa Grande (CE).}

Após as discussões teóricas, torna-se importante analisar os usos culturais da cultura, ou seja, o turismo cultural nas localidades enquanto processos identitários e sociais. É necessário lembrar, que este artigo trata da preservação e reutilização da identidade e do legado cultural, através da inserção da população local no processo de gestão da atividade turística.

\section{Casa da Cultura e Biblioteca Pública de Boa Esperança (MG)}

Este trabalho pretende despertar a atenção para se implementar ações conjuntas entre a indústria turística e a população local de modo a conceber o respeito e a proteção à identidade cultural e à memória. $\mathrm{O}$ caso a seguir aborda a experiência da Casa da Cultura e Biblioteca Municipal de Boa Esperança, Minas Gerais, e do Conselho de Patrimônio Histórico e Cultural do mesmo município.

A cidade de Boa Esperança está localizada no sul do estado de Minas Gerais, às margens do Lago de Furnas. Segundo o site Portal Boa Esperança Online, o município possui 47.038 habitantes de acordo com o ultimo censo. A cidade dispõe de vários atrativos turísticos, como o próprio Lago de Furnas - Lago dos Encantos, a Serra de Boa Esperança, o Festival Nacional da Canção, o Campeonato Brasileiro de Jet Ski e a Casa da Cultura, a qual será objeto de estudo nessa seção. 
Figura 1: Lago de Furnas, Boa Esperança, Minas Gerais.

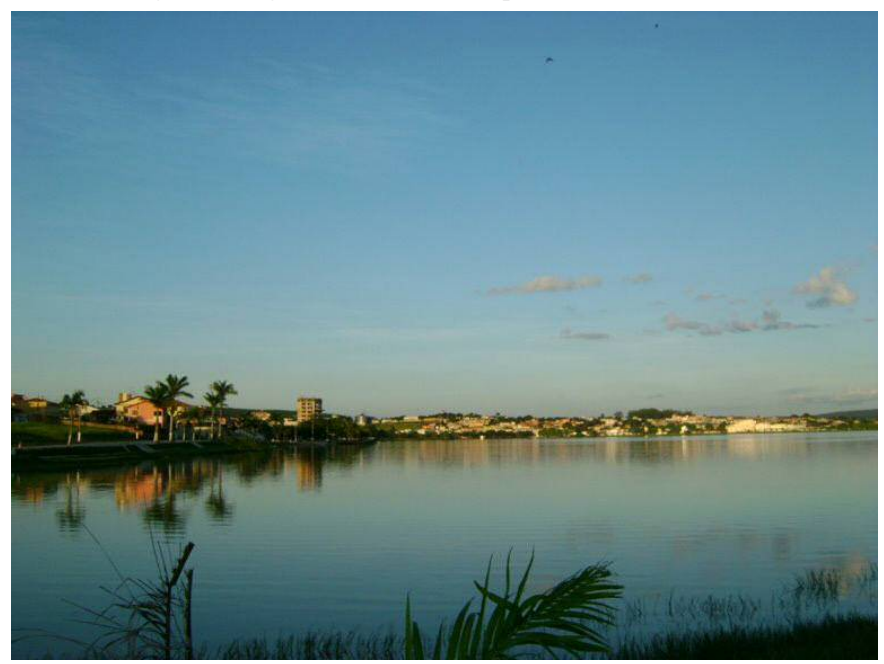

Fonte: arquivo do autor.

A Casa da Cultura está localizada na Rua Coqueiral, $\mathrm{n}^{\circ}$ 131, no centro de Boa Esperança. Nessa instituição, funciona, desde 1988, a Biblioteca Municipal da cidade, que fica no primeiro andar do estabelecimento. No segundo andar fica o acervo e o memorial da cidade.

Há também a Casa da Cultura, um prédio com 15 cômodos, construído em estilo Neocolonial que abriga documentos históricos importantes da cidade, fotos antigas e uma sala especialmente montada em homenagem a Lamartine Babo, que homenageou a Serra da Boa Esperança em uma de suas músicas (Portal Boa Esperança Online).

A Casa da Cultura tem como objetivo resguardar, proteger e preservar a memória e história da comunidade de Boa Esperança, para que a população visite e conheça sua própria história e herança cultural. Esta acolhe o Memorial Fotográfico Enéas, o Memorial Lamartine Babo, o Memorial Jacintho Felizali, o Memorial Newton-Freire Maia e o Memorial Dr. Joaquim Vilela. Esse acervo está aberto à visitação das oito horas da manhã às dezessete horas, de segundas às sextas-feiras. 
Figura 2: Casa da Cultura e Biblioteca Municipal, Boa Esperança, Minas Gerais.

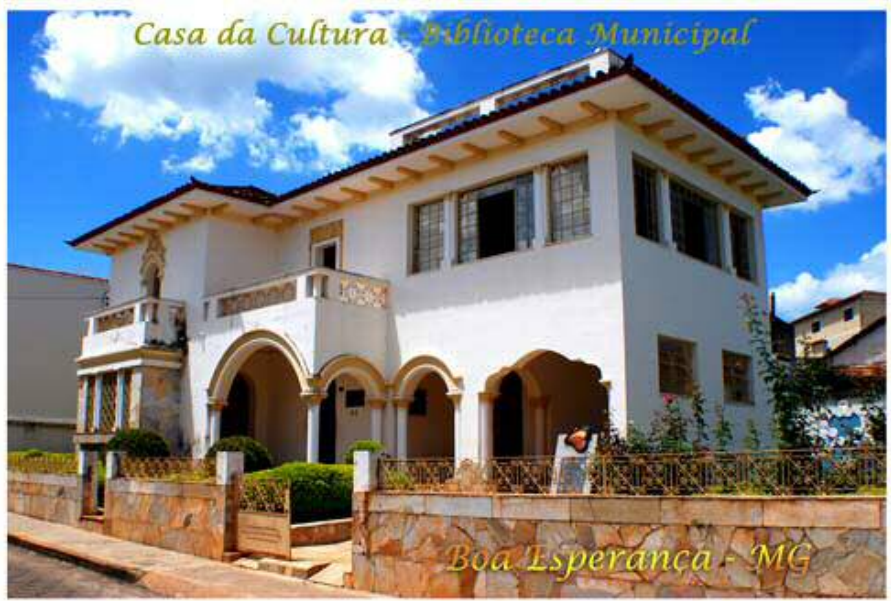

Fonte: $<$ http://www.boaesperanca-mg.com/images/stories/postcards/casadacultura.jpg $>$

A Biblioteca Pública desenvolve várias atividades sociais como: "A Semana de Leitura", na qual é comemorada o "Dia do Livro", quando alunos de várias escolas visitam a Biblioteca; o aniversário da Biblioteca, que é comemorado no dia 26 de Maio, com a participação das escolas da cidade. Há, também, muitas exposições de livros novos e doados pela Secretaria Municipal de Educação; exposições de trabalhos sobre folclore aberta ao público; e a "Biblioteca na Praça - A Biblioteca leva o livro até você", na qual é exposto todo o acervo da biblioteca na praça principal da cidade para que a população tenha melhor acesso.

Além da Biblioteca, localizada no primeiro andar da Casa da Cultura, há também o acervo que fica no segundo andar, onde é possível encontrar toda a história da cidade, memória, acontecimentos e documentos sobre pessoas importantes e famosas do município. No entanto, nem tudo ocorre de maneira próspera como parece, pois são poucos os moradores que visitam a Casa e que procuram saber de sua história e sua memória. Raros são os que procuram conhecer e que dão valor à sua herança cultural, e baixa também é a participação da população local nas reuniões do Conselho de Patrimônio Histórico e Cultural da cidade que são realizadas na Casa da Cultura. 
O primeiro autor deste artigo participou de uma dessas reuniões em Janeiro de 2009, quando estava realizando um estágio no Departamento de Turismo na Prefeitura Municipal de Boa Esperança. Nesta reunião, o ponto de pauta era a mudança dos membros gestores do conselho, mas para isso, precisavam de novos membros que quisessem compor a nova gestão. Porém, estavam preocupados, pois ninguém na comunidade manifestava o interesse em participar e ser membro, o que, por sua vez, deixavam os integrantes atuais bastantes preocupados, pois precisavam continuar a proteger, conservar, preservar e valorizar o seu legado histórico e cultural.

Observa-se que na Casa da Cultura é tudo muito bem organizado, limpo, tudo feito com muito cuidado e carinho. Contudo, é pesaroso que a comunidade não queira participar e valorizar tamanha riqueza. Diante do quadro apresentado, torna-se evidente a importância de discutir os usos da cultura enquanto processo social e identitário. O turismo, nesta localidade, poderia ser uma ação afirmativa que busca de conscientizar e demonstrar o valor do patrimônio para os seus habitantes. Eis um caso que as representações sociais, mesmo que inventadas, podem auxiliar no processo cultural no sentido do pertencimento.

\section{Fundação Casa Grande: Memorial do Homem Kariri, Nova Olinda (CE)}

A Fundação Casa Grande: Memorial do Homem Kariri, localizada em Nova Lima, Ceará, foi criada em 1992 com o objetivo de promover a inserção da população local em projetos sociais e nas atividades desenvolvidas pela Fundação. Dessa forma, essa instituição tem como missão a formação cultural de jovens e crianças da região, com a finalidade de levar uma educação contextualizada ao "mundo do sertão", mas não qualquer mundo, e sim um mundo que proporcione o "empoderamento da cultura e da cidadania".

Segundo o site dessa fundação, a "sua criação se deu a partir da restauração da primeira Casa da Fazenda Tapera, hoje cidade de Nova Olinda, ponto de passagem da estrada das boiadas que ligava o Cariri ao sertão dos Inhamuns, no período da civilização do couro, final do século XVII". A metodologia de trabalho dessa organização visa a sensibilização dos sentidos (ver, ouvir, fazer e conviver) da população, proporcionando acesso a um conteúdo de qualidade por meio de quatro programas, denominados: Memória, Artes, Comunicação e Turismo, os quais têm o objetivo de desenvolver 
atividades interdisciplinares.

Figura 3: Fundação Casa Grande - Memorial do Homem Kariri

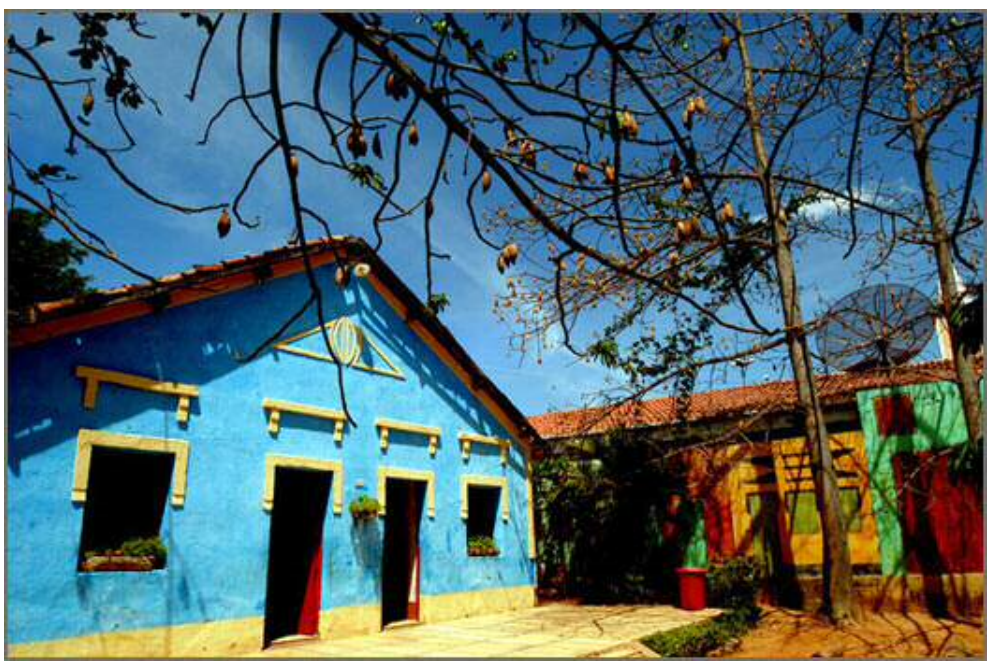

Fonte: Augusto Pessoa - <http://www.fundacaocasagrande.org.br/principal.php $>$

O Programa de Artes busca desenvolver a pesquisa étnica musical das lendas e dos mitos da Chapada do Araripe, onde se precedeu o Memorial do Homem Kariri. Este programa tem como objetivo sensibilizar as crianças através das artes e qualidade de conteúdo e incentivar a produção artística. O Programa de Comunicação tem por finalidade produzir materiais educativos e formar leitores, ouvintes e telespectadores. Com a criação da Rede de Crianças Comunicadoras Língua Portuguesa, este programa se difundiu e uniu o Brasil ao Moçambique e à Angola com o apoio da UNICEF - Fundo das Nações Unidas para a Infância. Essa rede tem como intuito integrar crianças e jovens de países de língua portuguesa, produzindo a comunicação entre eles e debatendo temas como os direitos das crianças e dos adolescentes, difundindo a diversidade cultural.

A Fundação Casa Grande é considerada uma experiência de sucesso, e devido a isto, muitas pessoas vão conhecer de perto o projeto da Fundação. Foi nesse cenário que surgiu o Programa de Turismo, para coordenar ações e potencializar o considerável número de turistas que a FCG tem atraído. Em 2006, segundo informações do site oficial 
da Fundação, eles receberam cerca de

28.050 pessoas, nove vezes a população urbana da cidade de Nova Olinda. Para atender a esta demanda, a Fundação Casa Grande criou junto aos pais uma cooperativa (COOPAGRAN) para comercializar a Casa Grande como um destino turístico e forma meninos e meninas para o receptivo turístico: recepcionistas, guias de campo e relações públicas. (Site Oficial da Fundação)

Dessa forma, realiza-se na Casa Grande o "turismo de conteúdo", no qual os turistas têm acesso aos laboratórios de conteúdo e às atividades desenvolvidas nos laboratórios de produção.

Nos Laboratórios de Conteúdo se encontram a Gibiteca, Biblioteca, laboratório de informática, DVDteca, discoteca e Educação Patrimonial. Nos Laboratórios de Produção se localizam os laboratórios de TV, Teatro, Rádio, Editora e Memorial. Segundo o site oficial da FCG "O laboratório do Memorial do Homem Kariri promove a formação de Recepcionistas mirins, com aulas de arqueologia, conservação do patrimônio, mitologia e museologia".

Como foi visto nos dados acima, retirados do site oficial da Fundação, a FCG desenvolve um trabalho social de considerável importância na região do Cariri, em Nova Olinda, Ceará. Em ações conjuntas com crianças, jovens e adultos locais, desenvolvem os Programas de Memória, Artes, Comunicação e Turismo, através dos Laboratórios de Conteúdo e Produção. O trabalho de formação educacional leva as crianças e jovens ao "mundo do sertão", e despertam neles o sentimento de pertença e conhecimento de sua história, memória e de sua herança cultural. As crianças têm acesso à biblioteca, aos laboratórios audiovisuais, informática, teatro, rádio, editora e educação patrimonial, na qual são conscientizadas a valorizar e proteger os bens que lhes pertencem.

Devido à tamanha demanda de visitantes, a FCG em ações conjuntas com os pais das crianças e jovens da Fundação, criaram uma cooperativa para apresentar a Casa Grande como destino turístico. Eles fizeram cursos de capacitação para meninos e meninas em serviços turísticos, como cursos para recepcionistas, guias de campo e 
relações públicas. Portanto, a FCG agrega a população no planejamento e gestão de suas atividades, fornecendo a educação desde as crianças e jovens aos pais, engajando-os a participarem no desenvolvimento de suas atividades e dando suporte, conhecimento e valorização ao seu patrimônio.

Noronha (2008), em sua dissertação, afirmou que para as crianças da FCG, a memória é objeto de conhecimento.

Através de suas vivências, meninos e meninas adquirem o hábito de preservar os achados arqueológicos para a história da humanidade, sabem por que o fazem e explicitam esse fato nos diálogos empreendidos com os visitantes, principalmente quando estão apresentando as peças do museu. (Noronha, 2008, p. 144).

No museu, as peças expostas propiciaram/propiciam a "observação", que levou/leva ao "registro", descrição escrita de cada objeto, feita pelas crianças da Casa. As peças continuam a ser "exploradas", mesmo depois de expostas, pois é apropriando-se de seus significados (em constante construção) que meninos e meninas passam a compor historinhas, músicas, desenhos e compartilhar todo aprendizado com os visitantes que adentram a $O N G$ (Noronha, 2008, p. 145-146).

A Fundação mantém parcerias com a Fundação Araripe, Banco do Nordeste, UNESCO - Organização das Nações Unidas para Educação, a Ciência e a Cultura, Ministério da Cultura, BNDES - Banco Nacional de Desenvolvimento Econômico e Social, e Governo do Estado do Ceará, entre outros. 


\section{CONSIDERAÇÕES FINAIS}

Como foi visto ao longo deste artigo, o turismo pode proporcionar a valorização, o sentimento de pertença, auto-estima, construção identitária, geração de trabalho e renda, conhecimento, proteção e preservação dos bens culturais de uma comunidade e/ou de um povo, desde que seja bem utilizado no uso social da cultura. Caso contrário, pode causar grandes danos, como preconceito, sentimento de inferioridade, desigualdade social, descaracterização das tradições e degradação do patrimônio.

A opção pelo desenvolvimento turístico deve conciliar-se aos objetivos de manutenção do patrimônio, do uso cotidiano dos bens culturais e da valorização das identidades culturais locais. O uso turístico deve atuar no sentido do fortalecimento das culturas. Assim, a atividade turística é incentivada como estratégia de preservação do patrimônio em função da promoção de seu valor econômico (MTur, 2006, p.9).

Este trabalho buscou analisar a preservação e proteção do legado cultural através da inserção da população local. Por quê? Em primeiro lugar, se os "donos" destes bens não se preocupam em preservá-lo, em salvaguardar sua memória, e em valorizar e amar o que são deles, quem vai fazer isso? Em segundo lugar, é importante que a comunidade se engaje sim no desenvolvimento do turismo, pois os atrativos são os bens que lhes pertence. Por último, a participação da população pode proporcionar conhecimento aprendizado e conscientização sobre a história e a origem de seu povo, sobre seus direitos, e sobre o que os pertence.

Muitos indivíduos não têm conhecimento de suas origens, mitos, histórias, tradições, cultura e muito menos do rico patrimônio que lhes pertencem e do seu valor. Essa conscientização pode ser concebida com a inserção dos habitantes locais na atividade turística.

Todavia, nem tudo é tão simples como parece. Por meio dos estudos e pesquisas bibliográficas, foi identificado com o desenvolvimento deste trabalho, dois problemas comuns em localidades turísticas e em sua gestão participativa. O primeiro é a exclusão dos autóctones nas atividades por parte dos servidores e gestores de turismo. O segundo, ao contrário, na maioria das vezes, são os residentes locais que não se prontificam a 
participar, eles não têm interesse em saber, compreender, dar sugestões e apoio ao desenvolvimento local através do turismo.

A proposta de desenvolvimento local participativo implica a democratização da vida social, através da mobilização da sociedade para a gestão compartilhada do desenvolvimento em processo, na democratização do poder local exercida nos mecanismos e canais de participação social, no reforço e na ampliação das organizações sociais, na promoção de parcerias e na existência de um sistema de informações aberto e descentralizado (Jara apud Manfredini, 2005, p. 48).

É notório que um problema depende do outro. Não adianta, por exemplo, os gestores convocarem a comunidade para dar sugestões, cursos de capacitação, se os residentes não se prontificarem a participar. Como também não adianta os autóctones se engajarem, se os gestores de turismo não derem espaço a eles.

Então, o que se pode fazer diante dessa problemática? A princípio é importante que os profissionais de turismo se conscientizem da importância que têm enquanto agentes sociais. Segundo, é preciso que se conscientizem da necessidade da inserção da população local para o planejamento e gestão da atividade turística, por meio de ações conjuntas entre ambos. A partir daí, esses profissionais devem convocar a população para reuniões e conselhos, primeiramente, com o intuito de conscientizá-los sobre a relevância de sua participação, sobre o valor de sua herança cultural, e desta como produto turístico de conhecimento e cultura, através da Educação Patrimonial. Por conseguinte, é necessário que os profissionais exponham o planejamento, os atrativos e o andamento da atividade turística na comunidade, solicitando sugestões e opiniões dos residentes.

Por fim, para que seja possível a inserção dos indivíduos locais, é necessário que forneçam cursos de capacitação em turismo e em áreas como comunicação, receptividade, cultura local, inclusão digital, gestão e idiomas. Todavia, não adianta oferecer a capacitação se não houver oportunidades de trabalhos locais, ou seja, é importante que haja emprego para eles, ou melhor, que haja a inserção dessa comunidade no mercado de trabalho turístico, visando não apenas a empregabilidade, mas, principalmente, a melhoria da qualidade de vida, por meio da inserção social dessa população. 
Passando por todos esses procedimentos, na tentativa de inserir a população local, cabe então, a esta, o interesse e a vontade de se inserir, participar, se envolver, de cuidar, planejar e organizar o seu patrimônio como atrativo turístico, de modo que não seja degradado e que se mantenha preservado e protegido.

O planejamento participativo parte de uma leitura do nosso mundo na qual é fundamental a idéia de que nossa realidade é injusta e de que essa injustiça se deve à falta de participação em todos os níveis e aspectos da atividade humana. A instauração da justiça social passa pela participação de todos no poder. Isto quer dizer que a construção de uma sociedade nova, a superação da crise, se quisermos seguir no mesmo modo de falar, passa pela participação de todos. Significa, também, a participação no poder que é o domínio de recursos para realizar sua própria vida, não apenas individualmente, mas grupalmente. O planejamento participativo é o modelo e a metodologia para que isto aconteça. Enquanto instrumento e metodologia, isto é, enquanto processo técnico, abre espaços especiais para as questões políticas (Gandin, 2001)

O planejamento participativo, realizado pela comunidade juntamente com os setores públicos e a indústria turística, é o melhor meio de minimizar os impactos no local receptor. Nota-se, no entanto, em alguns casos, que apesar dos esforços para que haja participação da população, esta não se engaja no processo de planejamento e desenvolvimento do turismo.

Uma das limitações deste estudo é que não foi possível identificar o porquê da complexidade da inserção da comunidade local e o motivo da falta de interesse em participarem do planejamento turístico. Seria necessária uma investigação mais aprofundada com a população residente de um local turístico, para que assim se obtenha novos resultados a respeito. Sugere-se então, a realização de novos estudos nessa linha de pesquisa, para que se alcance maior participação no planejamento do turismo em um local receptivo, enquanto representação da realidade, cuja cultura é norteadora dos seus aspectos sociais e identitários. 


\section{BIBLIOGRAFIA}

Barretto, M. (2002) Turismo e Legado Cultural. Papirus, Campinas.

Barretto, M.. (1995) Manual de Iniciação ao Estudo do turismo. Papirus, Campinas.

Batista, C. M. (2005) Memória e Identidade: Aspectos relevantes para o desenvolvimento do turismo cultural. Caderno Virtual de Turismo, volume 5, $\mathrm{n}^{\circ} 3$.

Biblioteca Municipal e Casa da Cultura. Disponível em: <http://www.boaesperanca. org/index.php/boa-esperanca/pontos-turisticos/biblioteca-municipal>. Acesso em: Junho de 2011.

Boa Esperança - Guia de viagem, dicas e onde ficar / Férias Brasil. Disponível em: $<$ http://www.feriasbrasil.com.br/mg/boaesperanca/>. Acesso em: Junho de 2011.

Burke, P. (1995) Cultura Popular na Idade Moderna. Schwarcz Ltda, São Paulo.

Burns, P. M. (2002) Turismo e Antropologia: uma introdução. Chronos, São Paulo.

Camargo, H. L. (2002) Patrimônio Histórico e Cultural. Aleph, São Paulo.

Castro, C. A. P. (2002) Sociologia Aplicada ao Turismo. Atlas S. A., São Paulo.

Chartier, R. (1990) A história cultural entre práticas e representações. Difel / Bertrand, Lisboa / Rio de Janeiro.

Coriolano, L. N. (2006) Espaço, poder e exclusão: contexto econômico-social do patrimônio cultural do lugar turistificado. In: MARTINS, Clerton (Org.). Patrimônio cultural: da memória ao sentido do lugar. Roca, São Paulo.

Coriolano, L. N. M. T. (2009) O Turismo Comunitário no Nordeste Brasileiro. In: Bartholo, R. Sansolo, D. G. Bursztyn, I. (orgs). Turismo de Base Comunitária: diversidade de olhares e experiências brasileiras. Letra e Imagem, Brasília, pp. 277-288.

Da Matta, R. (1981) Você tem Cultura?. Artigo publicado no Jornal da Embratel, Rio de Janeiro.

Fundação Casa Grande - Memorial do Homem Kariri. Disponível em: <http://www. fundacaocasagrande.org.br/principal.php $>$. Acesso em: Junho de 2012.

Gandin, D. (2001) A prática do planejamento participativo.Vozes, Petrópolis.

Geertz, C. (1989) A interpretação das culturas. Guanabara, Rio de Janeiro.

GEOSFERA - Divulgação Especial - Casa Grande. Disponível em: <http://geosfera. vilabol.uol.com.br/casagrande.htm>. Acesso em: Junho de 2010.

Hall, S. (2006) A Identidade Cultural na Pós-Modernidade. DP\&A, Rio de Janeiro.

Krippendorf, J. (2003) Sociologia do Turismo. Aleph, São Paulo.

Hobsbawn, E; Ranger, T. (Orgs). (1984) A invenção das tradições. Trad.: Celina Cardim Cavalcanti. Paz e Terra, Rio de Janeiro.

Malinowski, B. (1975) Uma teoria científica da cultura. Zahar, Rio de Janeiro.

Manfredini, C. (2005) Participação Comunitária em Projetos de Desenvolvimento Local: um estudo no bairro dos Marins, Piquete/SP. Dissertação (Mestrado em Gestão e Desenvolvimento Regional) - Departamento de Economia, 
Contabilidade e Administração, Universidade de Taubaté, Taubaté. Disponível em: <http://www.ppga.com.br/mestrado/2005/manfredini-cintia. pdf $>$. Acesso em: 28 de maio de 2010.

Martins, C. (2006) Patrimônio Cultural: da memória ao sentido do lugar. Roca, São Paulo.

Matheus, C. E; Moraes, A. J; Caffagni, C. W. A. ( 2005) O Envolvimento da Comunidade: as primeiras abordagens. In: Matheus, C. E. Moraes, A. J. Caffagni, C. W. A. (orgs). Educação Ambiental para o Turismo Sustentável: vivências integradas e outras estratégias metodológicas. Rima, São Carlos.

Martins, C \& Leite, L. (2006) Cultura, religiosidade popular e romarias: expressões do patrimônio imaterial. In: MARTINS, Clerton (Org.). Patrimônio cultural: da memória ao sentido do lugar. Roca, São Paulo.

Meneses, U. T. B. (1996) Os "usos culturais" da cultura. Contribuição para uma abordagem crítica das práticas e políticas culturais. In: YAZIGI, Eduardo. Turismo, paisagem e cultura. Hucitec, São Paulo.

Menezes, J. N. (2004) História e Turismo Cultural. Autêntica, Belo Horizonte.

Ministério do Turismo de Brasil. (2006) Turismo cultural: orientações básicas. / Ministério do Turismo, Secretaria Nacional de Políticas de Turismo, Departamento de Estruturação, Articulação e Ordenamento Turístico, Coordenação Geral de Segmentação. Ministério do Turismo, Brasília.

Nora, P. (1993) Entre memória e história: a problemática dos lugares. Trad.: Yara Aun Khoury. Projeto História, n. 10, Dez, pp. 7-28.

Noronha, I. L. A. (2008) Fundação Casa Grande - Memorial do Homem Kariri: Cotidiano, saberes, fazeres e as interfaces com a educação patrimonial, João Pessoa/PB. Dissertação (Mestrado em Educação Popular, Comunicação e Cultura) - Departamento de Educação, Universidade Federal da Paraíba, João Pessoa. Disponível em: <http://www.ce.ufpb.br/ppge/Dissertacoes/dissert08/ ISABELLE\%20DE\%20LUNA\%20ALENCAR/Funda\%e 7\%e3o\%20 Casa\%20Grande\%20-\%20Memorial\%20do\%20Homem\%20Kariri-\%20 Cotidiano,\%20.pdf>. Acesso em: Junho de 2010.

Paes, M. T. D. (2009) Patrimônio Cultural, Turismo e Identidades Territoriais: um olhar geográfico. In: Bartholo, R. Sansolo, D. G. Bursztyn, I. (orgs). Turismo de Base Comunitária: diversidade de olhares e experiências brasileiras. Letra e Imagem, Brasília, pp. 162-176.

Paoli, M. C. (1992) Memória, História e Cidadania: o direito ao passado. In: O Direito à Memória: Patrimônio Histórico e Cidadania. Secretaria Municipal de Cultura / Departamento do Patrimônio Histórico, São Paulo.

Pessoa, M. A \& Rabinovici, A. (2009) Inserção Comunitária e as Atividades do Turismo. In: Neiman, Z. Rabinovici, A. (orgs). Turismo e Meio Ambiente no Brasil. Manole Ltda, Barueri.

Portuguez, A. P. (2004) Turismo, Memória e Patrimônio Cultural. Roca, São Paulo. 
Portal Boa Esperança OnLine. Disponível em: <http://www.boaesperanca.com.br/ noticia.php?id=1>. Acesso em: Junho de 2012.

Sant'Anna, D. A; Oliveira, M. T. C; Berenstein, S. G. (2001) Gestão participativa para um turismo sustentável: o caso da costa do descobrimento. Secretaria da Cultural e Turismo, Salvador.

Vasconcelos, C. M. (2006) Turismo e museus. Aleph, São Paulo.

recibido: $24 / 01 / 2013$

aceptado: 30/04/2013

Arbitrado anonimamente 